limitation that the invention must not have been exhibited for any other competition. Each competitor must also attach to his entry form a copy of his patent specification, or, if the invention be not patented, a notice setting forth its aims and functions and, when possible, a résumé of its technical qualifications. If possible, actual models (in working order) are to be submitted, but if this cannot be done, permission may be obtained for their presentation by means of a plan. The jury decides whether the plan submitted is sufficiently explicit in itself to convey to experts, and to the public, a clear representation of the functions and operation of the invention. The total area allotted to each exhibit will as a rule not exceed one square metre, but by special application to the committee larger models may be exhibited. All inventions entered for the competition are dis. played in a special hall for the duration of the Fair and should be forwarded so as to arrive not later than May 5, addressed Foire de Paris, Concours d'Inventions, Porte de Versailles, Paris 15. The exhibits are classified under many headings, including engineering, medical apparatus, domestic economy, games, travel and camping, office equipment, publicity and education. Competitors whose inventions are not patented may apply for a certificate of guarantee affording protection in France for a period of twelve months from the opening date of the Fair. Entry forms can be obtained at the London Office of the Foire de Paris, 17 Tothill Street, Westminster, S.W.1, and must be completed by March 31 .

\section{Combustible Material in Electric Power Stations}

EARLY in this century, after a fire at Bristol, rubber-covered cables for switchboard work were rarely used. The recent inquiry on the fire at the Kingston Power Station should accelerate the demand for the use of non combustible materials alone in main power stations. It was stated in evidence that about 850 gallons of inflammable oil and about $14,000 \mathrm{lb}$. of solid compound fed the flames. Fires due to oil have been perhaps more numerous in America and Germany than in Great Britain; but recent events show the necessity of getting control of a fire in a power station at the earliest possible moment. The modern oil circuit-breaker (switch) has proved very trustworthy in practice. At its rated eapacity it will clear any electric faults with certainty; but in very exceptional circumstances it may fail. The chiefs of supply stations are now paying great attention to the problem of oil-less circuit breakers. Several foreign makers have for the last few years been successfully producing oil-less breakers, particularly the A.E.G. Co. in Berlin, the BrownBoveri Co. and the Oerlikon Co. in Switzerland. The A.E.G. Co. manufactures a special breaker called a chemical resin breaker for service in unattended substations where the air-blast type could not receive adequate supervision and maintenance. A very profitable and urgent line of inquiry for the industrial research worker would be to try to discover noncombustible liquids and solids of high insulating value for transformers, switches and electric wires. Some fairly satisfactory liquids and compounds have been found, but their cost at present is far too high for use in bulk. It is all a matter of finance. Textile glass has recently been invented. It seems probable that as a wrapping for electric wires it will have a great future.

\section{Agricultural Research and the Farmer}

A Broadsheet "Bringing Science to the Farm" issued by P E P (Political and Economic Planning) directs attention to defects in the present system of putting the results of agricultural research at the disposal of the farmer. Some of the difficulties are familiar in other attempts at the popularization of scientific discoveries, notably the superimposition of lecturing on research. Not only does such work impede actual research, but also research ability is by no means invariably linked to lecturing ability, and poor exposition may retard rather than help the spread of agricultural knowledge. The broadsheet urges a thorough overhaul of the provincial advisory service, which is not only seriously understaffed but has lagged behind the rapid diversification and specialization of the sciences concerned. Inadequate arrangements exist for liaison between the provincial advisers and research institutes not situated at their centre, or within their province as well as between the research institute and the farmer. The efficiency of the advisory service moreover depends primarily on the rateable value of the county and is controlled by the county agricultural committees, which cannot be expected to have the same scientific outlook and aims as the research and provineial advisory workers. County organizers do not always refer to the provincial advisers' problems which are beyond their own capacity, and the county organizer is often laden with many other duties besides advisory work. The broadsheet criticizes the annual reports of the research stations from the point of view of propaganda and also the manner of distribution of the official leaflets for farmers issued by the Ministry of Agriculture as well as the meagre use made of films, and lays special stress on the place of the educational services as the fundamental link between research and practice.

\section{Colloquium on Sex Hormones}

IN June 1937 a colloquium on sex hormones was held in Paris under the auspices of La Fondation Singer-Polignac. This colloquium was attended by men of science from France, Denmark, the United States, Canada, Great Britain, etc. The meeting lasted ten days, morning and afternoon sessions being held for the reading of papers on most days. The wide international representation of active investigators led to great interest being taken in the papers and to vigorous discussion. The papers presented, together with summaries of the discussions, were afterwards published in one volume for private circulation. They have now been republished in five numbers, each containing five papers, in the series of "Actualités Scientifiques et Industrielles" (Paris : Hermann et Cie). The first number appears under the general title "Les Propriétés des Hormones Sexuelles". The second number deals with "Ovula. 
tion, Menstruation, Gestation". The third contains papers dealing with the pituitary. The fourth is entitled "Régulations générales. Influence des facteurs nerveux et externes" ; and the fifth number contains papers on a variety of subjects such as pathology, toxicity, antihormones and cancer. The final publication of this material concludes the record of the colloquium, which will be long remembered by those taking part as a particularly happy and profitable occasion upon which La Fondation SingerPolignac should be most heartily congratulated.

\section{Lake District Roads}

Tre main object of the Friends of the Lake District is to have the Lake District made a National Park; but they insist on the necessity of guarding against the present tendency to undue development of motor-roads and motor-transport which would ruin the beauty and solitude of the district. The theme is developed at length in a pamphlet entitled "A Road Policy for the Lake District" published by the Friends of the Lake District, Ambleside. The essential Lake District is within a radius of some fifteen miles from the Langdale Pikes: this is the area that needs to be protected. There should be good motor-road access to this area and around it, but there should be no increase in the two or three good routes which go through this area. Moreover, in order to preserve the amenities, which give the Lake District much of its claim to preservation as a park, the width of roads should not be increased and through fast traffic thereby encouraged, dalehead roads which end in a cul-de-sac should not be made available for through traffic, and certain byroads should be closed entirely to motor-traffic. The pamphlet discusses these matters at length as well as the good and bad examples of road widening that have already been carried out. Above all, it advocates a policy that suits the requirements and amenities of the district rather than a standardized national policy which has little or no relation to local requirements.

\section{Insurance Against Natural Calamities}

THIS is a matter which has received a considerable amount of attention from time to time, and here and there premiums against such risk have been accepted, but in general, however, such risks are not taken by companies except for abnormally high premiums, for the simple reason that the place, time and destructive energy of the phenomena cannot be fore; told, nor do they occur with any regularity. The problem has been examined by $H$. Lanz-Stauffer (Revue pour l'étude des calamités, 1, No. 3 ; 1938). The first international conference on this topic, held in Paris on September 13-17, 1937, expressed the hope that research would be made into the problem of the application of the principles of insurance to natural calamities, an application considered until the present time not capable of realization. The author considers the problem from three different angles with regard to the Union Internationale de Secours: (1) with the Union as the insurer against the risk; (2) with the Union as the insured party against the risk; (3) with the Union encouraging in a general manner insurance against such calamities and contributing to its realization. The article may be commended to those concerned with insurance against damage by earthquakes, tornadoes and the like.

\section{Earthquakes Recorded at Tokyo}

WE have received the seismometrical report of the Earthquake Research Institute, Tokyo Imperial University, 1938, parts 1-2 (Jan. 1-June 30, 1938). This includes a first list of twelve stations attached to the Institute together with their latitude and longitude co-ordinates to the nearest second of arc, and their distances in kilometres from Tokyo. Following this is a table of twenty-two earthquakes sensible in Tokyo during the period under consideration. It would be an improvement if the headings to the columns in this table were given in English as well as in Japanese. Next is a map on a square of approximately $3^{\circ}$ edge having Tokyo at the centre, showing the distribution of the epicentres. It is notable that these are elongated in a direction north-east-south-west, and otherwise fairly uniformly distributed. Eight are submarine and off the north-east coast of the main island of Japan. Finally there are twelve reproductions of seismograms from the Tokyo (Hongo) station for the shocks of February 7, May 23 and June 6, six being normal and six acceleration seismograph diagrams, all very well reproduced. The publication provides valuable data for seismological studies.

\section{The Smithsonian Institution}

THE report of the Secretary of the Smithsonian Institution for the year ended June 30, 1938, refers to the completion in June of two full years of the Smithsonian radio programme in co-operation with the United States Office of Education (Publication 3489. Pp. viii + 117. Washington, D.C. : Government Printing Office, 1938). These educational broadcasts have covered the various fields of the Institution's activities-science, invention, history and art-and have been widely popular. An outstanding accession to the National Museum has been a collection of molluses obtained through the Francis Lea Chamberlain fund, which numbered more than a million specimens. Numerous specimens were brought back for the National Zoological Park by the National Geographic Society-Smithsonian Expedition to the East Indies. The Bureau of American Ethnology dispatched an expedition to South America to make extensive studies of the Indian tribes of the western part of that continent. The Division of Radiation and Organisms has developed an improved method for measuring plant growth substances concerned in the bending of plants towards the light, as well as a new automatic apparatus for measuring and recording photosynthesis continually, and an apparatus for the determination of chorophyll. The Smithsonian solar observing station on Mount St. Katherine in Egypt was abandoned, and construction of a new station on Burro Mountain, near Tyrone, New 